Article

\title{
The Role of Childhood Participation in Cultural Activities in the Promotion of Pro-Social Behaviours in Later Life
}

\author{
Brian Garrod $1, * \mathbb{C}$ and David Dowell ${ }^{2}$ \\ 1 School of Management, Swansea University, Swansea SA1 8EN, UK \\ 2 School of Management, University of St Andrews, St Andrews KY16 9RJ, UK; djd9@st-andrews.ac.uk \\ * Correspondence: brian.garrod@swansea.ac.uk
}

Received: 8 June 2020; Accepted: 13 July 2020; Published: 17 July 2020

check for updates

\begin{abstract}
Cultural organisations often serve as guardians of cultural heritage and, as such, cultural sustainability depends on their ongoing vitality. Many organisations in the cultural sector are, however, presently experiencing intense financial pressures. With their traditional sources of funding being progressively cut off, such organisations are focusing increasingly on monetary donations and the volunteering of time on the part of the general public to help plug the financial gap. Promoting and managing such pro-social behaviours can, however, be costly activities in themselves, so it is critical for cultural organisations to be able to target those segments of the public with the greatest propensity to give. This study sets out to address that need. The findings indicate that individuals who were involved in cultural activities as children are statistically more likely to volunteer their time in later life, not only with cultural organisations but also with good causes in general. In certain circumstances, this is also true of donating money. The cultural organisations benefiting from these pro-social behaviours need not be those with which the individual was involved in their childhood; nor need they be associated with the same form of culture. Importantly, continuous involvement in an activity from childhood into adulthood is not a necessary pre-condition for pro-social behaviour in later life.
\end{abstract}

Keywords: pro-social; volunteering; donation; culture; participation; children

\section{Introduction}

While the concept of sustainability has its roots in environmental thinking, it has become abundantly clear over the last three decades that sustainability considerations reach far beyond the ecological into the economic and socio-cultural realms. Cultural sustainability is hence widely considered to be vital for the wellbeing of individuals in the present generation and those to come [1]. Social capital is also understood to be an important driver of sustainable development, and an important way in which this is practiced is through participation in activities provided by the so-called "cultural sector" [2].

At its broadest definition, the cultural sector comprises museums, art galleries, theatres, historic buildings, libraries, and a variety of other organisations that serve as stewards and promoters of a society's cultural sustainability [3]. Cultural organisations curate and care for tangible elements of culture, such as historical artefacts and works of art, practice and perpetuate intangible forms of cultural heritage, such as literature, music and dance, and they educate society about the form, function and value of their cultural treasures. They are also a vital part of the tourism industry, serving as attractions that induce people to visit the destination and spend their money there [4].

Many such organisations are, however, coming under intense financial pressure at the present time [5]. The consequences of the global COVID-19 pandemic in 2020 imply not only a season of lost 
revenue but also, more crucially, a projected long period of deep economic recession. As such, they are likely to see fewer visitors in the future, as well as to find that their funders are less forthcoming with financial support. While some organisations are striving to continue their operations online, through virtual tours, this in no way makes up for the lost ticket, hospitality, and merchandise revenues they would otherwise have received. Many also have concerns that virtual attendance does not achieve the same quality of outcomes for the visitor. It would be no exaggeration, therefore, to suggest that the cultural sector is undergoing an existential crisis [6], which many will not survive [7], while those that remain may need to scale back their activities considerably [8]. Were this to happen, society would inevitably lose out on the contributions such organisations make to maintaining cultural sustainability.

Faced with poor trading conditions and the increasing scarcity of public funding, many cultural organisations are therefore increasingly reliant on donations of money and the volunteering of time for their financial survival. The drivers of such pro-social behaviours are, however, still poorly understood $[9,10]$. Attracting donations and recruiting volunteers are, meanwhile, costly activities in themselves. Cultural organisations are therefore in great need of ways to target their activities to those members of the public with the greatest propensity to engage in pro-social behaviours of this kind [11].

Another strategy in times of financial stress is to cut costs and, as such, many cultural organisations are looking to cut back on their youth programmes. Cultural organisations have long appreciated the value of childhood participation in developing long-term, on-going involvement in cultural activities. Indeed, Oskala et al. [12] argue that childhood participation in cultural activities has a range of positive outcomes. First, there may be immediate payoffs for the child participants in the form of educational and emotional benefits, including the development of creative-thinking skills and the nurturing of self-confidence [13-15]. This has sometimes been referred to as the "Mozart effect" [16]. Second, there may be long-term impacts with regard to long-term participation in culture, such as the life-long enjoyment of culture and the positive benefits to the cultural sector that flow from this: for example, the securing future audiences for their work $[12,17,18]$. Third, there may be broader benefits for society in the longer term, such as reductions in crime and other anti-social behaviours $[19,20]$. Clearly, these benefits will at least in part be foregone to society if cultural organisations cut back on their youth programmes.

The purpose of this paper is to consider these two problems together in order to investigate whether a joint solution may be found. It has long been known that adult participation in cultural activities can promote pro-social behaviours such as the donation of money and the volunteering of time to cultural organisations. Such effects have also been detected empirically among young people participating in cultural activities. McArthur and Law [21], for example, found that arts-based youth programmes can promote the adoption of pro-social behaviours among attendees. No studies have yet, however, examined how far cultural participation during childhood may result in people having a greater propensity to engage in pro-social behaviour as adults. If such links can be established, cultural organisations should be advised to build and retain strong programmes for engaging young people, even if they do not seem to immediately "pay off" in terms of encouraging the participants to continue with the cultural activity in their young adult life. Cultural organisations often find such programmes expensive, especially during times of austerity, but they may prove to be worth retaining if they help to promote pro-social behaviour among the recipients when they attain adulthood. If the propensity to donate and/or volunteer is independent from continued cultural participation, then such programmes could be worthwhile even if the young people in question do not continue with that cultural activity into adulthood.

This paper will therefore address the following research questions:

1. What effect, if any, does childhood involvement in cultural activities have on the propensity to volunteer time as an adult to good causes in general?

2. What effect, if any, does childhood involvement in cultural activities have on the propensity to volunteer time as an adult to causes specifically in the cultural sector? 
3. What effect, if any, does childhood involvement in cultural activities have on the propensity to donate money as an adult to good causes in general?

4. What effect, if any, does childhood involvement in cultural activities have on the propensity to donate money as an adult to causes specifically in the cultural sector?

Before proceeding, it is important to note that what properly constitutes a "cultural activity" is the subject of significant debate: proposed definitions range from the very narrow to the very broad [22]. In van der Ark and Richards' [23] study, for example, cultural activities are defined as visits to cultural heritage attractions, including museums, historic buildings, architecture, and art exhibitions and attractions that pertain to the performing arts. DiMaggio and Mukhtar [24], meanwhile, include attendance at classical music concerts, jazz performances, opera, musical theatre, non-musical theatre, ballet, visual art exhibits at museums or galleries, arts and craft fairs, historic sites, and modern dance. Similarly, Upright [25] uses attendance at galleries, musical, classical, theatre, dance, and opera; a classification that is also used by others such as López-Sintas and Katz-Gerro [26].

Definitions such as these are limited not only by focusing mainly on "high" culture but also because they tend to define cultural participation simply as attending a cultural event or performance. People can, however, participate directly in particular cultural activities by practicing them. The present study therefore defines as cultural participation, (i) visiting such places as, inter alia, museums and galleries, places of artistic performance (such a theatres and concert halls), historic sites and libraries, and (ii) undertaking in cultural and artistic activities such as, inter alia, reading, drawing, painting, creative writing, playing musical instruments, acting, dancing, and singing. This definition includes a mixture of "high" and "low" culture, as well as a mixture of activities that involve participation that is sometimes defined as active (such as going to the library) and passive (attending the theatre). It is certainly not comprehensive: for example, it may be considered that watching films or playing video games are cultural activities in modern society. It should be noted, however, that the above definition is determined by the dataset used in this study (as explained below). It is acknowledged that it may be desirable to collected data on a different basis in future studies so as to allow the definition of "culture" to be otherwise shaped or expanded, if so desired.

\section{Literature Review}

This section is divided into two parts. The first considers the extant literature on the links between childhood and adult participation in culture and the arts. The picture that emerges is one in which childhood participation is a major determinant of cultural participation in later life. What this literature tends to overlook, however, is whether there is an effect on pro-social behaviour as adults. Nor does the extant literature pay great attention to whether this pro-social behaviour is focused on the cultural sector or diffused among good causes more generally. The literature also has little to say with regard to the circumstances in which each of these pro-social behaviours may be more or less prevalent. The second part of this section therefore sets out to review the theoretical case for such links. Two specific pro-social behaviours that are of considerable interest to cultural organisations are focused upon: the giving of time (volunteering) and the giving of money (donation).

\subsection{Starting Young}

There is a growing body of evidence to suggest that childhood participation in culture and the arts significantly increases the propensity for adult cultural participation. Oskala et al. [12] found that childhood involvement in culture and the arts statistically increases the chances that the individual will also be involved in that same activity during adulthood. This may either be because the child has continued with the cultural activity into adulthood or because he or she has returned to it after having lapsed for a period of time. This finding is strongly supported by Elsley and McMellon [17] and research undertaken for the Scottish Government [27], both of which suggested similar linkages. Gray [18], meanwhile, used survey data from the US to explore the relationship between those taking 
art classes as a child (under 12 years of age) and their subsequent visits to art museums as adults, concluding that "early exposure results in later participation" [18] (p. 87).

With regard to the processes involved in this linkage, however, there is much less clarity. Some studies focus on motivations (often couched in terms of the balance of costs and benefits); others on character and pre-dispositions (such as family background, ethnicity, education, personality traits). Nagel and Ganzeboom [28], for example, use data from the Netherlands to show that both schooling and family background can have a positive impact on the propensity for people to participate in cultural activities as adults, with the latter having an effect three times greater than the former. Their study also found a high degree of consistency between cultural participation when an individual is aged 14 and aged 30. Such evidence tends to suggest that family background is the most important factor in explaining why children who participate in culture end up doing so as adults. It is debatable, however, whether this is because the family is a source of acculturation or simply because some families encourage their children to pursue cultural activities while for others it is simply "not what we do" [29].

Links have also been made between cultural capital and education, as well as non-educational outcomes, specifically that arts participation can have positive effects on people as they mature [30]. Indeed, using the same dataset (albeit drawn from a different year), one study has shown that cultural capital transmission takes part between parents and their children [31]. Robson [32] suggests that the acquisition of cultural capital can help children's educational attainment, especially when a passion for culture is rewarded by teachers. There is evidence to suggest that children who have a background in cultural attendance, and who have acquired cultural capital in their family home life, are more likely to engage in further education, and feel that education is less threatening [33]. This is argued to be as a result of cultural capital preparing those fortunate to have acquired it to better navigate the education system [34]. Educational achievement itself can be viewed as a form of economic capital insofar as it can readily be converted into money through career advancement. Cultural capital can also be turned into social capital if it allows access to networks where cultural familiarity and expertise is valued (while those without it are excluded) through what Bourdieu called the capital multiplier [2]. Belonging to such networks can, in turn, provide access to jobs or information about jobs, investment opportunities, and so on, which can then be converted into economic capital [32]. This is echoed by other studies which suggest post education success and childhood acquisition of cultural capital are linked [33].

The available literature therefore suggests strong links between childhood participation in cultural activities and the continuation of such participation into adulthood. Higher levels of social capital lead to stronger engagement with the common good, including donations [35]. The literature also notes that childhood cultural participation is likely to bring personal benefits to the individual through the building up of economic and social capital. This raises the question of whether childhood participation in cultural activities may be significantly connected with pro-social behaviour as an adult.

\subsection{Pro-Social Behaviours}

Pro-social behaviours in this study are defined in this paper as the giving of one's time (i.e., volunteering) and/or money (i.e., making donations) to good causes. Other pro-social behaviours are possible, but they are considered outside of the scope of this paper: not least for reasons of data availability.

\subsubsection{Volunteering}

As public funding for culture has become increasingly difficult to acquire, volunteering has become a major economic lifeline for many such organisations [36,37]. Indeed, it has been argued that many cultural organisations, venues, and events would not be able to survive financially without being able to use (unpaid) volunteer workers [38].

There is a view that there are many factors that affect volunteering [39]. The literature of volunteering does not, however, have much to say about whether there may be a connection between 
childhood involvement in cultural activities and the individual's tendency to volunteer as adults. Instead, the antecedents of volunteering have usually been approached from the perspective of what motivated the volunteer first to come forward to volunteer and then to continue in that capacity. There is little consistency in the empirical findings with regard to volunteering motivations. Bussell and Forbes [40], for example, outline a wide variety of motives for volunteering, ranging from wishing to "give back" to an organisation that helped a family member in a time of crisis to having the chance to wear a uniform. The latter of these motives may be linked to a need for affiliation with others. Warburton and Gooch [41], meanwhile, found that, in the context of environmental volunteering, older age groups often take a "generative" approach, i.e., their volunteering is based on a feeling of responsibility to leave a maintained or even better world for future generations. This includes the desire to leave something of lasting value, for themselves and others, to care about others and to feel personally valued. Thus far, however, the literature has failed to consider the extent to which exposure to and encouragement in cultural pursuits as a child might pre-dispose that person to pro-social behaviour in the form of volunteering as an adult.

\subsubsection{Donation of Money}

As with the volunteering of time, the literature on the motivations for making donations of money is largely silent when it comes to examining the role of childhood upbringing in pre-disposing such behaviour in adulthood. This is surprising given that knowledge of such information would clearly be useful to help organisations find the best ways to target their fund-raising efforts on the most likely, most "generous" donors.

Of the limited evidence on the relationship between childhood participation and adult donation, the paper by Bekkers [42] is perhaps most relevant to this study. It found that people who participate in voluntary associations as children tend to be more likely to donate to charitable causes as adults. It is important, however, to be aware that the mechanisms by which such socialisation has an effect on charitable giving in later life are still poorly understood. For example, in their later work, Bekkers and Wiepking [43] argue that this effect may be due to such children being more likely to be involved in those same voluntary associations when they become adults. As such, it may be contemporary affiliation to such associations that prompts charitable giving, rather than childhood participation per se. Other potential mechanisms tend to correlate strongly with other variables that are likely to be at work, such as reputational concern, the promise of psychological benefit or the passing on of pro-social values from parent to child.

Schlegelmilch et al. [44], meanwhile, reviewed the main empirical studies and found that money donations are generally greater among females, tending to rise gradually among both sexes to the age of 65 and then falling thereafter, and to increase consistently with disposable income. While not considering childhood participation in cultural activities, the study did examine the influence of previous volunteering experience (possibly as adults) and finds this to be an indicator of increased giving through raffle tickets. Other styles of giving-such as collections, television campaigns, sponsorship, and so on-do not clearly show such an effect. The work of Schlegelmilch et al. [44] on propensity to donate also examined personality, although debates clearly persist around whether there is such a thing as an altruism personality trait.

\subsubsection{Participation and Pro-Social Behaviour}

Participation in the cultural sector is argued to benefit children by boosting both their academic and social development [14]. Although in some cases not specifically linked to volunteering and donations of money, research has found links between childhood participation and aspects of pro-social behaviour. Some of this work has been done in the area of developmental education and psychology $[45,46]$. One view to emerge from this debate is that the propensity to engage in pro-social behaviour is the product of a person's inherent moral attitudes, rather than the exercise of some form of rational calculation [47]. For example, sharing behaviours at pre-school age have been shown to drive pro-social 
behaviours in teenage years, which is attributed to the development of attitudes related to caring for others and social justice [48]. Such views hold that through certain behaviours as a child, attitudes are formed that may affect latter behaviours, in this case pro-social behaviours.

One study that has tried to understand a causal link between youth activities and adult pro-social behaviour is Hart et al. [49]. In addition to predicting voting behaviours, undertaking extra-curricular activities in high school was found to have a significant effect on volunteering eight years after high school. Involvement with groups and activities was seen to develop social capital and pro-social attitudes [49]. Similarly, findings also suggest that adolescent engagement with the arts, music, dance, dramatic arts, and creative writing can influence adult engagement with volunteering [50]. Those involved at a young age should thus be more likely to involve themselves in volunteering in later life, meaning that cultural engagement will have a positive effect on pro-social behaviour in later life. The first hypothesis is, therefore:

Hypothesis 1 (H1). Involvement in cultural activities as a child will have a positive significant effect on the propensity to volunteer in later life.

The second hypothesis relates volunteering with the cultural sector specifically. The cultural volunteer may be seen as different to the mainstream volunteer [51]. It is therefore prudent to examine whether the cultural volunteer is influenced by childhood interactions with culture separately to mainstream volunteering. Indeed, if the results of the analysis are different for volunteering in general and volunteering in the cultural sector specifically, it might reasonably be concluded that the processes by which such outcomes come about are distinct. Indeed, the study by Wymer and Brudey [51] suggests that there are statistically significant differences in the values held by general volunteers and those specifically volunteering time with cultural organisations. More specifically, "salvation" was significantly less important an influence, while "a world of beauty," "an exciting life," and "freedom" were significantly more important. The authors go on to argue that volunteers tend to choose organisations that share their values. This raises important questions with regard to where such values are born and nurtured. One possibility is that they are developed during childhood participation in various cultural activities. Indeed, it has been suggested that participation in certain activities during childhood may cause an individual to lean towards pro-social engagement in particular areas in later life. For example, public speaking, representation, and community service during childhood are believed to influence the likelihood of later-life involvement with political groups [52]. Similarly, involvement with a civil-rights organisation can have an effect on participation in such causes later in life: for example, being involved in a youth organisation has a significant effect on the likelihood to attend political protests in adulthood [53]. This may suggest that volunteering with cultural organisations may be influenced by different drivers than general volunteering. The second hypothesis is, therefore:

Hypothesis 2 (H2). Involvement in the cultural sector as a child will have a positive significant effect on the propensity to volunteer in the cultural sector as an adult.

The influence of upbringing on donations has not been widely discussed in the literature and it would seem that the potential role of childhood participation in cultural activities specifically has hardly been considered at all. Moreover, most studies are limited to either volunteering or donating and are limited to a single or non-contextual setting without comparison. As such, the aim of this paper is to provide a greater understanding of the role of childhood participation in culture, and to better understand how it may affect pro-social behaviours directed at organisations both in the cultural sector and more widely. 
Much like volunteering, there is some evidence to suggest that affiliation as a younger person will lead to donations of money in later life. For example, alumni of universities often give money to them, and the amount can depend on the activities the individual participated in when studying [54]. Research on giving by alumni tends to indicate that their experience of the institution will affect giving. Such evidence relates to the experiences of young adults (university students) but may nevertheless provide some basis to expect similar linkages among youths and perhaps younger children. Moreover, if there are possible linkages from childhood cultural participation to the volunteering of time in later life, then it must be conceded that it is at least possible that the same kinds of links exist with regard to a similar pro-social behaviour, the donation of money. As such, the third and fourth hypotheses used in this study are:

Hypothesis 3 (H3). Involvement in cultural activities as a child will have a positive significant effect on the propensity to make donations in later life.

Hypothesis 4 (H4). Involvement in cultural activities as a child will have a positive significant effect on the propensity to make donations to the cultural sector in later life.

\section{Materials and Methods}

The data used for this research were taken from a national study into culture and sports participation in England, United Kingdom, entitled "Taking Part." The survey was conducted by the Department of Culture and Sport, in partnership with Sport England, the Arts Council England, English Heritage, and the Museums, Libraries and Archives Council. It was first conducted in 2005 and has been undertaken annually ever since. Data from 2012-2013 are used here, as this is the largest and most recent version of the survey available before the sample size was substantially reduced. The survey was administered by trained fieldworkers, with a sample derived in order to be representative of England as a whole. Respondents were drawn randomly from a national address database and approached via mail and then in person. The in-person interviews took around $45 \mathrm{~min}$ to complete. The total dataset was based on a survey of 9838 people, $55.5 \%$ of whom were female, and the mean age was 52.73 years. Of the total sample, $80 \%$ classified themselves as urban dwellers, $46.1 \%$ were married, $27.4 \%$ had children living in their household, and $41.8 \%$ were currently practicing religion.

Given the presence of dependent categorical variables, logit regression [55] was chosen as the method of data analysis. An odds ratio interpretation was used for reporting purposes. This combination of technique and interpretation method has successfully been used before in studies of pro-social behaviour [56] and is well recognised.

The dependent variables for the regression analysis comprised the following: "During the last 12 months, have you done any voluntary work?", "If you have volunteered, did you volunteer in a cultural sector?", "Have you donated money in last 12 months?" and "If you did give money, did you give it to the cultural sector?" Each variable was measured on a no/yes (0/1) scale. The two scales which measure the volunteering time and donating money to the cultural sector exclude all those who have not volunteered with or donated to the sector.

The independent variables concerned participation in cultural activities when growing up. These variables were binary variables, i.e., coded as no/yes (0/1). Participants in the survey could elect to complete a sports or cultural section (or both), with 4792 completing the cultural section, which measured their participation in cultural activities when they were young. Those relating to attendance at places of culture when growing up were as follows: "Go to museums or art galleries", "Go to the theatre or to see a dance or classical music performance", "Go to historic sites" (this includes historic attractions such as old buildings, historic parks and gardens and archaeological sites), "Go to the library". Those relating to the participation in cultural activities when growing up comprised: "Read books for pleasure/enjoyment" (i.e., not required for school or religious studies), "Draw or paint", "Write stories, poems, plays or music", "Play musical instrument(s), act, dance or sing". Two sets of 
variables are thus included in this study: the former referring to (more passive) attendance and the latter to (more active) participation. This is important since research has found that different forms of cultural participation have differing impacts on pro-social outcomes [57].

A number of control variables were included in the regression in order to enable the context to be taken into account. Indeed, the underlying cause-and-effect relationships between the dependent and independent variables are likely to be influenced by a number of covariates, and the addition of control variables to represent these is intended to enhance the overall explanatory power of the model. The first three were age, current income, and gender. These have often been used in previous studies dealing with pro-social giving behaviour [58]. Given the focus of the study on childhood activities, playing sports as a child was also included as a further control variable. Sports and cultural activities are assumed to be substitutes for the child's time. If the child is involved in sports, they are likely to have less time (and perhaps also less inclination) to participate in cultural activities. A fifth control variable, subjective evaluation of health, was also included to help control for people's ability to volunteer as adults $[59,60]$.

\section{Results}

\subsection{Descriptive Analysis}

The descriptive statistics of the sample measures (items) used for the independent variables are presented in Table 1. With regard to attendance at cultural venues as a child, the most commonly visited were museums and art galleries, followed by historic sites. For cultural activities undertaken as a child, reading books and drawing recorded the highest levels of participation.

Table 1. Frequencies table for variables.

\begin{tabular}{lcccc}
\hline Item & Volunteer No & Volunteer Yes (\%) & Donate No & Donate Yes (\%) \\
\hline Did not go to museums or art galleries & 1615 & $356(18.06)$ & 302 & $1669(84.68)$ \\
\hline Went to museums or art galleries & 2181 & $817(27.25)$ & 279 & $2722(90.70)$ \\
\hline $\begin{array}{l}\text { Did not go to the theatre or see a dance } \\
\text { or classical music performance }\end{array}$ & 2209 & $514(18.88)$ & 382 & $2341(85.97)$ \\
\hline $\begin{array}{l}\text { Went to the theatre or saw a dance or } \\
\text { classical music performance }\end{array}$ & 1587 & $659(29.34)$ & 199 & $2050(91.15)$ \\
\hline Did not go to historic sites & 1654 & $357(17.75)$ & 323 & $1688(83.94)$ \\
\hline Went to historic sites & 2142 & $816(27.59)$ & 258 & $2703(91.29)$ \\
\hline Did no go to the library & 1038 & $213(17.03)$ & 239 & $1012(80.90)$ \\
\hline Went to the library & 2758 & $960(25.82)$ & 342 & $3379(90.81)$ \\
\hline $\begin{array}{l}\text { Did not read books for } \\
\text { pleasure/enjoyment }\end{array}$ & 979 & $232(19.16)$ & 243 & $969(79.95)$ \\
\hline Read books for pleasure/enjoyment & 2817 & $941(25.04)$ & 338 & $3422(91.01)$ \\
\hline Did not draw or paint & 1899 & $539(22.11)$ & 309 & $2130(87.33)$ \\
\hline Drew or painted & 1897 & $634(25.05)$ & 272 & $2261(89.26)$ \\
\hline $\begin{array}{l}\text { Did not write stories, poems, plays or } \\
\text { music }\end{array}$ & 2633 & $667(20.21)$ & 469 & $2833(85.80)$ \\
\hline Wrote stories, poems, plays or music & 1163 & $506(30.32)$ & 112 & $1558(93.29)$ \\
\hline $\begin{array}{l}\text { Did not play musical instrument(s), act, } \\
\text { sing, dance }\end{array}$ & 2154 & $461(17.63)$ & 383 & $2235(85.37)$ \\
\hline $\begin{array}{l}\text { Played musical instrument(s), acted, } \\
\text { sung, danced }\end{array}$ & 1642 & $712(30.25)$ & 198 & $2156(91.59)$ \\
\hline
\end{tabular}

Note-Findings are based on the cultural subsample, and there are some missing cases reported here. 
Descriptive data on the four dependent variables are summarised in Table 2. With regard to the general sample, $24.29 \%(n=2387)$ had volunteered time in the previous 12 months, while $89.45 \%$ ( $n=8800)$ had donated some amount of money to one or more good causes. Based on the total sample for giving to the cultural sector, $7.91 \%(n=777)$ had volunteered time and $31.6 \%(n=3109)$ had donated money to the sector.

Table 2. Dependent variables.

\begin{tabular}{|c|c|c|c|c|}
\hline & \multicolumn{2}{|c|}{ Total Sample } & \multicolumn{2}{|c|}{ The Cultural Sector Only } \\
\hline & Total & $\%$ & Total & $\%$ \\
\hline Did not volunteer in the last 12 months & 7442 & 75.71 & 9052 & 92.09 \\
\hline Volunteered in the last 12 months & 2387 & 24.29 & 777 & 7.91 \\
\hline Did not give money in the last 12 months & 1038 & 10.55 & 6729 & 68.40 \\
\hline Gave money in the last 12 months & 8800 & 89.45 & 3109 & 31.60 \\
\hline
\end{tabular}

Note- table is based on the full sample.

\subsection{Relationship Between Childhood Attendance of Cultural Venues and Adult Pro-Social Behaviour}

The results of the logit regression analysis are summarised in Tables 3 and 4, which report the odds ratios (OR) and $p$-values calculated. Each of the regressions had a significant chi-square and post-tests revealed they had significant Wald tests $(p<0.001)$, indicating strong parameter fit, while the Homer-Lemeshow tests indicated that there was no evidence of a lack of fit $(p>0.05)$. Hence, each of the regressions is deemed suitable to report. In the discussion that follows, statistical significance will be reported at the $p<0.05$ level.

Table 3. Regression results for attending cultural venues.

\begin{tabular}{ccccccccc}
\hline & $\begin{array}{c}\text { All-Sector } \\
\text { Volunteering }\end{array}$ & \multicolumn{2}{c}{$\begin{array}{c}\text { Cultural } \\
\text { Volunteering }\end{array}$} & \multicolumn{2}{c}{$\begin{array}{c}\text { All-Sector } \\
\text { Donating }\end{array}$} & \multicolumn{2}{c}{$\begin{array}{c}\text { Cultural } \\
\text { Donations }\end{array}$} \\
\hline & OR & $p$-Value & OR & $p$-Value & OR & $p$-Value & OR & $p$-Value \\
\hline $\begin{array}{c}\text { Go to museums or art } \\
\text { galleries }\end{array}$ & 1.219 & 0.077 & 0.971 & 0.893 & 1.164 & 0.316 & 1.167 & 0.139 \\
\hline $\begin{array}{c}\text { Go to the theatre or to see } \\
\text { a dance or classical music } \\
\text { performance }\end{array}$ & 1.576 & 0.000 & 1.551 & 0.023 & 1.166 & 0.290 & 1.253 & 0.016 \\
\hline $\begin{array}{c}\text { Go to historic sites } \\
\text { Go to the library }\end{array}$ & 1.204 & 0.104 & 0.816 & 0.360 & 1.266 & 0.120 & 1.589 & 0.000 \\
\hline Play sports as a child & 1.434 & 0.005 & 0.776 & 0.310 & 1.782 & 0.000 & 1.360 & 0.008 \\
\hline Subjective health & 1.197 & 0.001 & 1.184 & 0.115 & 1.176 & 0.018 & 1.156 & 0.004 \\
\hline Age (years) & 0.996 & 0.122 & 0.988 & 0.015 & 1.021 & 0.000 & 1.007 & 0.004 \\
\hline Gender & 1.309 & 0.005 & 0.456 & 0.000 & 1.772 & 0.000 & 1.049 & 0.600 \\
\hline Income & 0.998 & 0.892 & 1.090 & 0.000 & 1.131 & 0.000 & 1.081 & 0.000 \\
\hline Constant & 0.062 & 0.000 & 0.234 & 0.026 & 0.168 & 0.000 & 0.039 & 0.000 \\
\hline
\end{tabular}

The effect on all-sector volunteering as an adult after attending cultural venues as a child was found to be statistically significant for going to the theatre or to see a dance or classical music performance, and for going to the library. Of the control variables, both gender and subjective health were found to be significant. The largest effect was for going to theatre or to see a dance or classical music performance $(\mathrm{OR}=1.576)$. This can be interpreted as meaning that someone who had attended such performances as a child was $57.6 \%$ more likely to volunteer their time as an adult. The next largest effect was going to 
the library $(\mathrm{OR}=1.434)$. Importantly, all variables other than age $(\mathrm{OR}=0.996)$ and income $(\mathrm{OR}=0.998)$ had a positive relationship with volunteering. The results for donating money to all sectors were rather different. Only going to the library and three of control variable (age, gender, and income) were found to be significant. Going to the library had the largest influence ( $\mathrm{OR}=1.782)$, implying that someone who went to the library when growing up is $78.2 \%$ more likely to donate money as an adult; next was gender $(\mathrm{OR}=1.772)$, which implied that being female had a significant and large positive impact on the propensity to make donations.

For volunteering time specifically in the cultural sector, only going to the theatre or to see a dance or classical music performance had a significant effect. Three of the control variables-gender, income, and age had significant effects on volunteering time specifically in the cultural sector. For donating money to the cultural sector, going to the theatre, going to historic sites, and going to the library all had significant and positive effects. Going to historic sites had the largest effect ( $\mathrm{OR}=1.589)$, followed by going to the library $(\mathrm{OR}=1.360)$. Of the control variables, subjective health, age, and income had significant effects, but these were almost neutral (OR is close to 1 ).

There were thus a number of contrasts between pro-social behaviour generally and in the culturally sector specifically. For volunteering time, going to the library, going to historic sites and going to museums/galleries were all significant for all-sector volunteering but insignificant for volunteering specifically in the cultural sector. Only going to the theatre or to see a dance or classical music performance was a significant predictor of volunteering both in general and specifically it the cultural sector. For donating money, going to the theatre or to see a dance or classical music performance and going to historic sites were significant predictors in the cultural sector specifically but not in all sectors generally. Meanwhile only going to the library was a consistent predictor both generally and specifically in the cultural sector. Going to museums or art galleries was not significant for volunteering time or donating money either generally in all sectors or in the cultural sector specifically.

\subsection{Relationship Between Childhood Participation in Cultural Activities and Adult Pro-Social Behaviour}

The regression results for childhood participation in cultural activities are summarised in Table 4. For the effect on all volunteering, writing stories, poems, plays, and music $(\mathrm{OR}=1.396)$ and playing musical instruments, acting, dancing, or singing $(\mathrm{OR}=1.623)$ had significant positive effects. Subjective health, age, and gender had significant effects as control variables.

Reading books for pleasure/enjoyment $(\mathrm{OR}=1.890)$ and writing stories, poems, plays, or music $(\mathrm{OR}=1.669)$ both had a significant impact with regard to all-sector donation of money. The odds ratios suggest that undertaking these activities as children will have an appreciable effect on the individual's propensity to donate in later life. All of the control variables were found to have a significant positive effect $(\mathrm{OR}>1)$, indicating that donation is more likely to be done by women and is affected by increasing age, income, and subjective health. Most interesting of all in this regression is that undertaking sport as a child has the largest significant effect on all-sector donation of money $(\mathrm{OR}=2.163)$.

Looking specifically at volunteering time in the cultural sector, none of the childhood participation variables had a significant effect. Age, gender, and income all had a significant effect. In the case of gender this is quite large $(\mathrm{OR}=0.437)$ and in favour of men. For donating money to cultural organisations, reading books for pleasure, writing stories, poems, plays, or music, and playing instruments, acting, dancing, and singing all had significant and positive effects. The largest effect was reading books $(\mathrm{OR}=1.606)$, followed by playing an instrument $(\mathrm{OR}=1.420)$ and writing stories $(\mathrm{OR}=1.309)$. Income and subjective health had a significant effect among the three control variables. 
Table 4. Regression results for undertaking cultural activities.

\begin{tabular}{cccccccccc}
\hline & \multicolumn{2}{c}{$\begin{array}{c}\text { All-Sector } \\
\text { Volunteering }\end{array}$} & \multicolumn{2}{c}{$\begin{array}{c}\text { Cultural } \\
\text { Volunteering }\end{array}$} & \multicolumn{2}{c}{$\begin{array}{c}\text { All-Sector } \\
\text { Donating }\end{array}$} & \multicolumn{2}{c}{$\begin{array}{c}\text { Cultural } \\
\text { Donations }\end{array}$} \\
\hline & OR & $p$-Value & OR & $p$-Value & OR & $p$-Value & OR & $p$-Value \\
\hline $\begin{array}{c}\text { Read books for } \\
\text { pleasure/enjoyment }\end{array}$ & 1.095 & 0.431 & 0.984 & 0.943 & 1.890 & 0.000 & 1.606 & 0.000 \\
\hline $\begin{array}{c}\text { Draw or paint } \\
\text { Write stories, poems, } \\
\text { plays, or music }\end{array}$ & 0.886 & 0.201 & 1.065 & 0.725 & 0.975 & 0.850 & 0.956 & 0.612 \\
\hline $\begin{array}{c}\text { Play musical } \\
\text { instrument(s), act, } \\
\text { dance, or sing }\end{array}$ & 1.623 & 0.000 & 1.405 & 0.069 & 1.162 & 0.278 & 1.420 & 0.000 \\
\hline $\begin{array}{c}\text { Play sports as a child } \\
\text { Subjective health }\end{array}$ & 1.316 & 0.079 & 1.720 & 0.115 & 2.163 & 0.000 & 1.331 & 0.056 \\
\hline Age (years) & 0.995 & 0.042 & 0.990 & 0.045 & 1.019 & 0.000 & 1.004 & 0.077 \\
\hline Gender & 1.217 & 0.047 & 0.437 & 0.000 & 1.536 & 0.002 & 0.931 & 0.443 \\
\hline Income & 1.000 & 0.988 & 1.082 & 0.001 & 1.136 & 0.000 & 1.086 & 0.000 \\
\hline Constant & 0.094 & 0.000 & 0.175 & 0.008 & 0.191 & 0.000 & 0.050 & 0.000 \\
\hline
\end{tabular}

\section{Discussion}

The use of both attendance and participation in culture as a child, in addition to general and culture specific pro-social behaviours, has generated some interesting findings. There were a number of contrasts between the predictors of all-sector volunteering and donations with respect to different forms of cultural engagement. Writing stories, poems, plays, or music predicted general volunteering, but not volunteering specifically in the cultural sector. Income only had a significant relationship with volunteering specifically in the cultural sector. For donating money, the pattern was similar, with only drawing/painting proving non-significant. The order of the effect sizes was slightly different, as were the magnitudes. With regard to donating money, the effect size was larger in the control variables, with all three significant for general donations but only age for donations to the cultural sector.

There were four general hypotheses developed for this research. These were developed around the research questions, which pertained to the influence of childhood attendance of cultural venues and participation in cultural activities on adult pro-social behaviours. For H1, going to the theatre, going to the library, writing stories, poems, plays or music, and playing musical instruments, acting, dancing, and singing all had a significant effect on the propensity to volunteer as an adult. There is thus some support for H1. However, with regard to the relationship same childhood variables on volunteering specifically with organisations in the cultural sector, only going to the theatre was found to have a significant effect. As such, $\mathrm{H} 2$ is less well-supported by the data.

Hypothesis $\mathrm{H} 3$ related to the propensity to donate money in later life to any sector, while $\mathrm{H} 4$ related specifically to donating money to the cultural sector. In terms of the effects on general donating money in later life, going to the library was the only attendance variable that was significant. With regard to participation in activities, two variables-reading books for pleasure and writing stories, poems, plays, or music - were found to be significant. There is thus evidence to support the proposition that both attending cultural venues and participating in cultural activities have a later-life effect on the all-sector donation of money. As such, $\mathrm{H} 3$ is supported. For H4, the effects of childhood attendance of cultural venues and participation in cultural activities on donating money specifically to the cultural sector, going to the theatre, going to historic sites, and going to the library were all significant predictors. Reading books for pleasure, writing stories, poems, plays, or music, and playing musical instruments, acting, dancing, or singing were all also significant predictors of later-life donations. $\mathrm{H} 4$ therefore finds 
support: childhood attendance of cultural venues and participation in cultural activities both influence the propensity to donate money to the cultural sector as an adult.

\section{Conclusions}

Previous research has linked childhood participation in cultural activities with adult participation in those same activities. Research also suggests that childhood participation in cultural activities has benefits with respect to the development of social capital and civic behaviours, which can benefit both the individuals taking part and society more broadly. Furthermore, the literature has investigated the determinants of certain pro-social behaviours on the part of adults: the main subject being the volunteering of time, with considerably less emphasis on the donation of money. What is missing is to determine whether there is an observable effect related to participation in cultural activities as a child on undertaking pro-social behaviours as an adult. The effect of going to cultural venues, such as libraries, museums, and historic sites, is also poorly investigated: research having focused to date mainly on participation in artistic activities, such as creative writing or playing musical instruments.

This paper set out to begin to fill the gap, focusing on two important pro-social behaviours: volunteering time and donating money. It has focused particularly on whether there is a relationship between childhood participation in culture and these pro-social behaviours in adult life and, if such a relationship does indeed exist, what form it may take. The nature of such a relationship, if indeed it exists, has special significance for cultural sustainability at the present time, when the cultural sector worldwide is facing what may well be an existential threat from a combination of continued austerity and economic disruptions as a result of the COVID-19 pandemic. The implication is that cultural organisations that are directly funded by governments may well find the public-funding environment even less generous towards them than it has been in recent times, while those that rely upon ticket sales for the bulk of their recurring revenues will need to rebuild their audiences in the post-COVID period. For some, perhaps many, it is already too late: they will be forced to scale down their activities or perhaps never even reopen. The implications for cultural sustainability are clear: society will have to do without many of the organisations that have hitherto curated, promoted, interpreted and helped to finance the sustaining of our cultural heritage.

The results of the analysis suggest that including volunteers and donors who visited cultural venues or participated in cultural activities as children may be a more efficient targeting strategy than those currently pursued by many cultural organisations. Existing organisational strategies to encourage both the volunteering of time and the donation of money tend to target older, female, and higher-income individuals [61]. The results presented here suggest that age and income tend to have a relatively small influence on people's propensity either to volunteer time or to donate money, while gender appears to have larger effects in some cases. Based on these findings, it might be argued that socio-demographic segmentation may not in itself be especially effective in comparison to targeting those who participated in cultural activities and went to cultural venues as children. This analysis does not, of course, take account of the amount of time or money individuals may volunteer or donate [44]: high-income people may have no greater propensity to volunteer time or donate money, but when they do so they may give more.

As a general strategy, targeting those who participated in cultural activities or went to cultural venues as children may thus be a useful additional form of targeting, in addition to targeting using the often-significant but generally less-powerful socio-demographic variables. While there are some differences with respect to the forms of participation and types of culture venue that are associated with later-life volunteering and donation, this broad finding is equally apposite for organisations within the cultural sector and those outside of it. The results suggest that those who participated in cultural activities or went to cultural venues as children may have a greater propensity to volunteer time or donate money, regardless of whether the organisation is seen as being part of the cultural sector. However, further research is required to examine why some forms of childhood cultural engagement do not seem to have a significant relationship with pro-social behaviour in later life, while others 
evidently do. In the meantime, it would be a sensible strategy for cultural organisations to focus on those forms of childhood which this study suggests do have a positive impact.

The details of the relationship do, of course, vary between those organisations specifically in the cultural sector and organisations in general. The results of the study suggest, for example, going to the library is significantly, positively, and substantially associated with volunteering time with organisations in general in later life, but the same cannot be said of volunteering time specifically with organisations in the cultural sector. Going to historic sites, on the other hand, is significantly, positively, and substantially associated with donating money to organisations in the cultural sector in later life; but the same is not true of donating money to good causes more generally.

Organisations seeking to recruit those willing to volunteer their time or to donate money might therefore consider supplementing their existing socio-demographic targeting strategies with additional efforts to attract those who participated specific cultural activities and went to certain cultural venues in their childhood. Nostalgic appeals could be one means of achieving this: for example, to use promotional materials that encourage potential volunteers and donors to recall their engagement with culture in childhood. This may assist in accessing people's "generative" motivations to volunteer time and donate money [41]. The results do not suggest that this pro-social behaviour will necessarily be directed at the same form of culture the adult participated in as child or necessarily the same venues they attended in their childhood. A museum might therefore wish to remind potential donors of money of their childhood visits to historic sites: those who went to historic sites as children are seen to be $58.9 \%$ more likely to donate money to cultural organisations in later life. An important proviso is that this does not necessarily take account of the amount of money the individual may donate: the odds ratio simply expresses their likelihood of donating money at all.

The results also highlight the importance of certain cultural organisations continuing to fund their children's and youth programmes, and this may be a way forward. Many organisations run such programmes, which can take many forms, from putting on special performances or exhibitions aimed at young people, to operating youth programmes such as youth theatre, orchestras, art classes and dance companies. In certain cases, expenditure on these programmes could actually be seen as a good investment, as the odds are that those who participate in them are appreciably more likely to "give back" when they are adults by giving their time as volunteers or their money as donors. This may be true even if their involvement lapses when they become adults, as is often the case. The seeds of pro-social behaviour have already been sown.

Governments and other funding organisations would therefore do well to support the cultural programmes of cultural organisations on this basis. Indeed, this study suggests that spending public money on such programmes may be a social investment of a kind, as the results show that childhood participation in culture has a significant relationship with pro-social behaviour by those individuals when they grow up. This pro-social behaviour is not just directed at organisations in the cultural sector but may benefit good causes in any sector. In short, childhood participation in cultural activities and attendance of cultural venues makes for more pro-social adults. Exposing children to culture is, in this sense, an investment not only for the children themselves and for society at large: taking part as children leads to giving back as adults. While this is not a sufficient condition for the effective pursuit of cultural sustainability, it is arguably a necessary condition, assuming that the current economic climate of austerity and scarce public funding is to continue. The economic implications of the global COVID-19 pandemic in 2020 give every indication that it will, and for some time to come.

There are some limitations with this study that imply the need for further research. First, there remains a need for longitudinal analysis. Using this form of analysis, tendencies in a subject's pro-social giving could be tracked over time. Critical moments of ceasing and resuming pro-social behaviour can be identified and analysed. This would allow for greater understanding of the effects of childhood involvement at various points in time and to estimate the strength of the effect over a person's life course. Second, the dataset is now somewhat old. It was not possible to use a newer Taking Part dataset because of changes in the sampling procedure, resulting in too small a subset 
of respondent who had completed the cultural section. Repeating this study using even older data does not, however, alter the general conclusion that childhood participation in cultural activities is positively associated with pro-social behaviours in later life. Third, the current study is based on the analysis of an existing "big" dataset. A bespoke survey could be conducted to allow more control variables to be included in the analysis. The current study only includes demographic variables as controls. The income control variable is particularly problematic in that it refers to the respondent's current income, rather than their family's income as a child. Family income is widely considered to be a significant determinant of childhood participation in cultural activities, while it may also have a positive influence on contemporary pro-social behaviour. This introduces the possibility that family income during childhood is at work as a confounding variable. While intended partly to help correct for this effect, the inclusion of current income may only partially address the problem because relatively high rates of social mobility in the UK mean that past and current income tend not to be closely correlated. It would also have been useful if the dataset had included attitude variables and further possible antecedents of pro-social behaviours in later life.

Author Contributions: Conceptualization, B.G. and D.D.; methodology, D.D.; formal analysis, D.D.; writing-original draft preparation, B.G.; writing-review and editing, B.G. and D.D. Both authors have read and agreed to the published version of the manuscript.

Funding: This research received no external funding.

Acknowledgments: The authors would like to thank the editors of the journal and the reviewers for their helpful comments.

Conflicts of Interest: The authors declare no conflict of interest.

Note: For further information on ethics, participant management and selection please see: https://www.gov.uk/ guidance/taking-part-information-for-survey-participants.

\section{References}

1. Di Fabio, A. The psychology of sustainability and sustainable development for well-being in organizations. Front. Psychol. 2017, 8, 1534-1540. [CrossRef] [PubMed]

2. Hampshire, K.R.; Matthijsse, M. Can arts projects improve young people's wellbeing? A social capital approach. Soc. Sci. Med. 2010, 71, 708-716. [CrossRef] [PubMed]

3. Loach, K.; Rowley, J.; Griffiths, J. Cultural sustainability as a strategy for the survival of museums and libraries. Int. J. Cult. Pol. 2017, 23, 186-198. [CrossRef]

4. Noonan, D.S.; Rizzo, I. Economics of cultural tourism: Issues and perspectives. J. Cult. Econ. 2017, 41, 95-107. [CrossRef]

5. Rex, B. Which museums to fund? Examining local government decision-making in austerity. Local Gov. Stud. 2020, 46, 186-205. [CrossRef]

6. BBC. Coronavirus: Arts Venues Welcome $£ 1.57 \mathrm{bn}$ Government Support. 6 July 2020. Available online: https://www.bbc.co.uk/news/entertainment-arts-53302415 (accessed on 7 July 2020).

7. Leask, A. How Tourism Destinations Can Rebuild after Coronavirus. The Conversation. 18 June 2020. Available online: https://theconversation.com/how-tourist-destinations-can-rebuild-after-coronavirus140969 (accessed on 15 July 2020).

8. Di Gaetano, L.; Mazza, I. "Better an egg today than a hen tomorrow" on the implications of deaccess policies for donations to museums. J. Cult. Econ. 2017, 41, 237-258. [CrossRef]

9. Gil-Lacruz, A.; Marcuello, C.; Saz-Gil, I. Individual and social factors in volunteering participation rates in Europe. Cross-Cult. Res. 2017, 51, 464-490. [CrossRef]

10. Neto, A.B.F. Charity and public libraries: Does government funding crowd out donations? J. Cult. Econ. 2018, 42, 525-542. [CrossRef]

11. Robson, A.; Hart, D. The post-Brexit donor: Segmenting the UK charitable marketplace using political attitudes and national identity. Int. Rev. Pub. Nonprof. Mark. 2019, 16, 313-334. [CrossRef]

12. Oskala, A.; Keaney, E.; Chan, T.W.; Bunting, C. Encourage Children Today to Build Audience for Tomorrow: Evidence from the Taking Part Survey on How Childhood Involvement in the Arts Affects Arts Engagement in Adulthood; Arts Council England: London, UK, 2009. 
13. Andersen, I.G.; Jæger, M.M. Cultural capital in context: Heterogeneous returns to cultural capital across schooling environments. Soc. Sci. Res. 2015, 50, 177-188. [CrossRef]

14. Catterall, J.S. The Arts and Achievement in at-Risk Youth: Findings from Four Longitudinal Studies; Research Report 55; National Endowment for the Arts: Washington, DC, USA, 2012. Available online: http://eric.ed.gov/?id= ED530822 (accessed on 15 July 2020).

15. Ovink, S.M.; Veazey, B.D. More than 'getting us through: A case study in cultural capital enrichment of underrepresented minority undergraduates. Res. Higher Educ. 2011, 52, 370-394. [CrossRef] [PubMed]

16. Beauvais, C. The 'Mozart Effect': A sociological reappraisal. Cult. Soc. 2015, 9, 185-202. [CrossRef]

17. Elsley, S.; McMellon, C. Starting Young? Links between Childhood and Adult Participation in Culture and Science: A Literature Review; Scottish Government Social Research: Edinburgh, UK, 2010.

18. Gray, C. Hope for the future? Early exposure to arts and adult visits to art museums. J. Cult. Econ. 1998, 22, 87-98. [CrossRef]

19. Guetzkow, J. How the Arts Impact Communities; Working Paper Series 20; Centre for Arts and Cultural Policy Studies, Princeton University: Princeton, NJ, USA, 2002.

20. Newman, T.; Curtis, K.; Stephens, J. Do community-based arts projects result in social gains? A review of the literature. Commun. Dev. J. 2003, 38, 310-322. [CrossRef]

21. McArthur, D.; Law, S.A. The Arts and Prosocial Impact Study: A Review of Current Programs and Literature. 1996. Available online: https://eric.ed.gov/?id=ED444896 (accessed on 15 July 2020).

22. Barrett, M.S.; Smigiel, H. Awakening the 'sleeping giant'? The arts in the lives of Australian families. Int. J. Educ. Arts 2003, 4, 1-16.

23. Van der Ark, L.A.; Richards, G. Attractiveness of cultural activities in European cities: A latent class approach. Tour. Manag. 2006, 27, 1408-1413. [CrossRef]

24. DiMaggio, P.; Mukhtar, T. Arts participation as cultural capital in the United States, 1982-2002: Signs of decline? Poetics 2004, 32, 169-194. [CrossRef]

25. Upright, C.B. Social capital and cultural participation: Spousal influences on attendance at arts events. Poetics 2004, 32, 129-143. [CrossRef]

26. López-Sintas, J.; Katz-Gerro, T. From exclusive to inclusive elitists and further: Twenty years of omnivorousness and cultural diversity in arts participation in the USA. Poetics 2005, 33, 299-319. [CrossRef]

27. Scottish Government. People and Culture in Scotland 2008: Results from the Scottish Household Survey Culture and Sport Module 2007/2008; National Statistics: Edinburgh, UK, 2009.

28. Nagel, I.; Ganzeboom, H. Participation in legitimate culture: Family and school effects from adolescence to adulthood. Neth. J. Soc. Sci. 2002, 38, 102-120.

29. Everett, M.; Barrett, M.S. Investigating sustained visitor/museum relationships: Employing narrative research in the field of museum visit studies. Visit. Stud. 2009, 12, 2-15. [CrossRef]

30. Martin, A.J.; Mansour, M.; Anderson, M.; Gibson, R.; Liem, G.A.; Sudmalis, D. The role of arts participation in students' academic and nonacademic outcomes: A longitudinal study of school, home, and community factors. J. Educ. Psychol. 2013, 105, 709-727. [CrossRef]

31. Scherger, S.; Savage, M. Cultural transmission, educational attainment and social mobility. Sociol. Rev. 2010, 58, 406-428. [CrossRef]

32. Robson, K. Teenage time use and investment in cultural capital. In Working Papers of the Institute for Social and Economic Research; University of Essex: Colchester, UK, 2003.

33. De Graaf, N.D.; De Graaf, P.M.; Kraaykamp, G. Parental cultural capital and educational attainment in the Netherlands: A refinement of the cultural capital perspective. Sociol. Educ. 2000, 73, 92-111. [CrossRef]

34. Goldthorpe, J.H. 'Cultural capital': Some critical observations. Sociologica 2007, 1. [CrossRef]

35. Oto-Peralías, D.; Romero-Ávila, D. The consequences of persistent inequality on social capital: A municipal-level analysis of blood donation data. Econ. Lett. 2007, 151, 53-57. [CrossRef]

36. Bendle, L.; Patterson, I. Serious leisure, career volunteers and the organization of arts events in a regional Australian city. Int. J. Event Manag. Res. 2008, 4, 1-11.

37. Manetti, G.; Bellucci, M.; Como, E.; Bagnoli, L. Investing in volunteering: Measuring social returns of volunteer recruitment, training and management. Volunt. Int. J. Vol. Nonprof. Org. 2015, 26, 2104-2129. [CrossRef]

38. García-Mainar, I.; Marcuello, C. Members, volunteers, and donors in nonprofit organizations in Spain. Nonprof. Vol. Sect. Quart. 2007, 36, 100-120. [CrossRef] 
39. Studer, S.; von Schnurbein, G. Organizational factors affecting volunteers: A literature review on volunteer coordination. Volunt. Int. J. Vol. Nonprof. Org. 2013, 24, 403-440. [CrossRef]

40. Bussell, H.; Forbes, D. Understanding the volunteer market: The what, where, who and why of volunteering. Int. J. Nonprof. Vol. Sect. Market. 2002, 7, 244-257. [CrossRef]

41. Warburton, J.; Gooch, M. Stewardship volunteering by older Australians: The generative response. Local Environ. 2007, 12, 43-55. [CrossRef]

42. Bekkers, R. Charity begins at home: How socialization experiences influence giving and volunteering. In Proceedings of the 34th Annual ARNOVA-Conference, Washington, DC, USA, 17-19 November 2005.

43. Bekkers, R.; Wiepking, P. Who gives? A literature review of predictors of charitable giving. Part one: Religion, education, age and socialisation. Vol. Sect. Rev. 2011, 2, 337-365. [CrossRef]

44. Schlegelmilch, B.B.; Love, A.; Diamantopoulos, A. Responses to different charity appeals: The impact of donor characteristics on the amount of donations. Eur. J. Market. 1997, 31, 548-560. [CrossRef]

45. Denault, A.S.; Poulin, F. Intensity and breadth of participation in organized activities during the adolescent years: Multiple associations with youth outcomes. J. Youth Adolesc. 2009, 38, 1199-1213. [CrossRef]

46. Fredricks, J.A.; Eccles, J.S. Is extracurricular participation associated with beneficial outcomes? Concurrent and longitudinal relations. Dev. Psychol. 2006, 42, 698-713. [CrossRef]

47. Youniss, J.; Yates, M. Youth service and moral-civic identity: A case for everyday morality. Educ. Psychol. Rev. 1999, 11, 361-376. [CrossRef]

48. Sherrod, L.R. Recognizing civic engagement as a critical domain of human development. Res. Hum. Dev. 2015, 12, 312-318. [CrossRef]

49. Hart, D.; Donnelly, T.M.; Youniss, J.; Atkins, R. High school community service as a predictor of adult voting and volunteering. Am. Educ. Res. J. 2007, 44, 197-219. [CrossRef]

50. Obradović, J.; Masten, A.S. Developmental antecedents of young adult civic engagement. Appl. Dev. Sci. 2007, 11, 2-19. [CrossRef]

51. Wymer, W.W., Jr.; Brudney, J.L. Marketing management in arts organizations: Differentiating arts and culture volunteers from other volunteers. Int. J. Arts Manag. 2000, 2, 40-52.

52. McFarland, D.A.; Thomas, R.J. Bowling young: How youth voluntary associations influence adult political participation. Am. Sociol. Rev. 2006, 71, 401-425. [CrossRef]

53. Terriquez, V. Training young activists: Grassroots organizing and youths' civic and political trajectories. Sociol. Perspect. 2015, 58, 223-242. [CrossRef]

54. Bruggink, T.H.; Siddiqui, K. An econometric model of alumni giving: A case study for a liberal arts college. Am. Econ. 1995, 39, 53-60. [CrossRef]

55. Hair, J.F.; Black, W.C.; Babin, B.J.; Anderson, R. Multivariate Data Analysis: A Global Perspective, 7th ed.; Pearson: Upper Saddle River, NJ, USA, 2010.

56. Nesbit, R. The influence of major life cycle events on volunteering. Nonprof. Vol. Sect. Quart. 2012, 41, 1153-1174. [CrossRef]

57. Leroux, K.; Bernadska, A. Impact of the arts on individual contributions to US civil society. J. Civil Soc. 2014, 10, 144-164. [CrossRef]

58. Wilson, J. Volunteering. Ann. Rev. Sociol. 2000, 26, 215-240. [CrossRef]

59. Choi, N.G.; Kim, J. The effect of time volunteering and charitable donations in later life on psychological wellbeing. Ageing Soc. 2011, 31, 590-610. [CrossRef]

60. Dury, S.; De Donder, L.; De Witte, N.; Buffel, T.; Jacquet, W.; Verté, D. To volunteer or not: The influence of individual characteristics, resources, and social factors on the likelihood of volunteering by older adults. Nonprof. Vol. Sect. Quart. 2015, 44, 1107-1128. [CrossRef]

61. Gilheany, P. Charities should also target Donor Dave, not just Donor Dorothy. The Guardian. 25 May 2016. Available online: https://www.theguardian.com/voluntary-sector-network/2016/may/25/charitiesfundraising-target-donor-dave-not-just-donor-dorothy (accessed on 15 July 2020).

(C) 2020 by the authors. Licensee MDPI, Basel, Switzerland. This article is an open access article distributed under the terms and conditions of the Creative Commons Attribution (CC BY) license (http://creativecommons.org/licenses/by/4.0/). 